\title{
Prevalence of Kuhn Frontal Cells in Frontal Sinusitis: A Literary Review
}

\author{
Raam Deepak ${ }^{1}$, Padmanabhan Karthikeyan ${ }^{2}$, Nikhil Sivanand $^{3}$
}

\begin{abstract}
Background: The relationship between frontal cells to frontal sinus disease pathology remains an understudied area. Caucasian population were studied in most previous studies of the pneumatization pattern of the frontal recess, whereas there are very few reports on the prevalence of frontal recess cells and their relation with frontal sinusitis in India. The purpose of this review is to determine the frequency of occurrence of frontal cells and to determine whether the size of the frontal isthmus or the presence of frontal cells is related to the presence of frontal sinus disease in various articles. There are a lot of studies that appear in the Western literature, but there are less Indian studies on this subject. Materials and methods: In this article, we reviewed around 25 various randomized, clinical, and experimental trials conducted between 1940 and 2016 and which were published in various Indian and American journals. The literature search was conducted after using the key words chronic rhino-sinusitis, Kuhn frontal cells, frontal recess, frontal sinusitis, functional endoscopic sinus surgery, and computed tomography from Pubmed, Cochrane, Proquest, and Google Scholar.

Conclusion: There was no significant relation between any particular frontal recess cell and the size of the nasofrontal isthmus as the cause for frontal sinusitis in majority of studies, and therefore we concluded that various factors, along with the pattern of pneumatization and mucosal edema, contributed to the pathogenesis of chronic frontal sinusitis.

Keywords: Chronic sinusitis, Computerized tomography, Frontal cells, Frontal ostium, Frontal sinus.

Annals of SBV (2020): 10.5005/jp-journals-10085-8123
\end{abstract}

\section{INTRODUCTION}

The frontal recess (FR) has middle turbinate as its medial boundary, lamina papyracea as its lateral limit, bulla posteriorly, and frontal and maxillary bone in its anterior wall, which thickens antero-superiorly to form the frontal beak. This area was coined as the nasofrontal region, which is now described as the frontal recess. ${ }^{1}$

Killian in 1903 first described the FR, and a little later Van Alyea described in detail, the pneumatization of this region. The frontal recess has a complex anatomy that resembles and inverted funnel. The frontal ostium forms its apex. ${ }^{2}$ The structural makeup of frontal recess is dependent on the pattern of pneumatization of the anterior ethmoid cells in this area. These cells are anterior group of ethmoidal cells that grow into the frontal sinus and are thus called frontal cells. ${ }^{3}$

An acute frontal sinus infection can easily turn into a chronic disease if any of the various frontal cells along the nasofrontal isthmus gets infected. Previous studies have looked at a number of these cells, namely, agger nasi cell (ANC), frontal bullar cell $(F B C)$, frontal cell $(F C)$, suprabullar cell $(S B C)$, interfrontal sinus septal cell (IFSSC), and supraorbital ethmoidal cell (SOEC) and have found relation between the involvement of these cells and the incidence of frontal sinusitis. ${ }^{4}$ Most studies on the pneumatization pattern of the frontal recess cells have been carried out on Caucasian population. There are only very few reports on comparing the presence of frontal recess cells and its relation to chronic frontal sinusitis in India. The present study was done to analyze the frequency of occurrence of Kuhn frontal cells, its relationship with frontal cells, and frontal sinus disease from literature from various articles. Although the frontal recess anatomy has been described extensively in the literature appearing in the West, there are few studies from the Indian Subcontinent on this subject. \begin{tabular}{l}
\hline${ }^{1-3}$ Department of Otorhinolaryngology, Mahatma Gandhi Medical \\
College and Research Institute, Sri Balaji Vidyapeeth, Puducherry, India \\
Corresponding Author: Padmanabhan Karthikeyan, Department \\
of Otorhinolaryngology, Mahatma Gandhi Medical College and \\
Research Institute, Sri Balaji Vidyapeeth, Puducherry, India, Phone: +91 \\
9443381302 , e-mail: karthikent73@gmail.com
\end{tabular}

How to cite this article: Deepak R, Karthikeyan P, Sivanand N. Prevalence of Kuhn Frontal Cells in Frontal Sinusitis: A Literary Review. Ann SBV 2020;9(2):53-55.

Source of support: Nil

Conflict of interest: None

\section{Materials and Methods}

Systematic review of all journals indexed in Pubmed, Cochrane, Proquest, and Google Scholar between 1940 and 2016 using the key words chronic rhino-sinusitis, Kuhn frontal cells, frontal recess, frontal sinusitis, functional endoscopic sinus surgery, and computed tomography were analyzed and conclusions drawn.

\section{Review of Literature}

\section{Historical Review}

Leonardo de Vinci, in 1489, was the first to recognize the existence and illustrate the morphology of frontal region, closely followed by Berengario de Carpi in 1522, who described the frontal bone region as having "two tables within which there is a notable vacuity so as to not to weigh down the body." Volcher Coiter of Holland, Dutch anatomist and physician (1534-1576), a pupil of Fallopius \& Eustachian, later, was the first to describe the frontal sinus with illustrations in publication. Killian first described frontal 
recess in 1903. Later, there was extensive writings and description of the anatomy and pneumatization pattern within the frontal sinus by Van Alyeas. ${ }^{2}$ Four different types of frontal cells were described by Bent and Kuhn as follows: the type I frontal cell is a single cell located above the agger nasi cell; type II frontal cells are a group of cells located above the agger nasi cell projecting within the frontal recess; the type III frontal cell is defined as a single massive cell arising above the agger nasi, pneumatizing cephaloid into the frontal sinus; and the type IV frontal cell is a loner cell located within the frontal sinus. ${ }^{5,6}$

\section{Computed Tomography Analysis of Frontal Cells}

Meyer et al. ${ }^{7}$ had determined the anatomic variants and prevalence of frontal cells and examined their relationships in a study of 768 computed tomography (CT) scans. They concluded that:

- Type I cells were found to be the common type of cells (14.9\%).

- The prevalence of frontal cells was found to be $20.4 \%$ among the study population undergoing the $\mathrm{CT}$ scan.

- Frontal cells are frequently associated with other anatomic variants, the most common cell being present being the agger nasi cell.

- While the presence of frontal cells can cause mechanical obstruction of frontal recess, it does not invariably lead to frontal sinusitis.

- Frontal sinusitis is more prevalent in people with type III and type IV Kuhn cells when compared to those without frontal cells ( $p$ value $<0.01$ ).

\section{Multiplanar Reconstructed CT in Depiction of Anatomy of Frontal Sinus}

The use of multiplanar CT scan images was studied by Kew et al. in order to better understand the depiction of the anatomy and its effect on surgical approach of frontal recess and sinus in 43 patients. $^{8}$ There was no statistically significant difference ( $p$ value $>0.05$ ) between the fronto-ethmoidal cells on parasagittal and coronal views on the CT images. ${ }^{9}$ Using both coronal and parasagittal reconstructed images greatly elucidates the anatomy of the frontal recess when compared to the usage of coronal images alone ( $p$ value $<0.001$ ), and this plays an important role in planning of the surgery involving the frontal recess in patients without frontal sinusitis. ${ }^{10}$

Lee et al. used 3-dimensional computerized tomography scans to describe frontal sinus pneumatization in 50 patients with no previous history of frontal sinus disease or any other conditions that influence frontal pneumatization ${ }^{11}$ and found the prevalence of the various types of cells to be as follows: agger nasi cells are the commonest anatomical variant found in $89 \%$ of the study population: type I frontal cells were found in $37 \%$ of the population, type II frontal cells were found in $19 \%$ of the population, type III frontal cells in $8 \%$, supraorbital ethmoidal cells in $62 \%$, suprabullar cell in $15 \%$, frontal bullar cell in $9 \%$, interfrontal sinus septal cell in $14 \%$, and recesses terminalis was found in $22 \%$ of the study population.

\section{Multiplanar CT Analysis of Frontal Recess Cells}

The prevalence of frontal recess cells and the occurrence of frontal sinusitis was studied by DelGaudio et al. using multiplanar reconstructed CT images in 106 patients. On investigation, frontal cells were absent in $67 \%$ of patients, and the number of both unilateral and bilateral cells was equal. ${ }^{1}$ Type I cells were the commonest cells found (18.4\%) followed by type III cells, which were found in $6.1 \%$ of the cases. Type IV and type II cells were the least common type of cells to be found, seen in $3.1 \%$ and $2 \%$ of the cases studied, respectively. No correlation was found between the presence of frontal cells and the incidence of frontal sinusitis in this study. ${ }^{12}$ However, a study done by Meyer et al. provides a contrasting picture, finding a greater incidence of chronic frontal sinusitis in patients with type III and type IV cells. ${ }^{7}$

Van Alyea et al. showed the incidence of frontal cells to be $40 \%$, a figure much higher than the actual incidence, but this can be explained by the fact that the study also included agger nasi cells, intersinus septal cells, and supraorbital ethmoid cells. ${ }^{2}$

Meyer et al., however, detected and reported the incidence of frontal cells in $20.4 \%$ of patients studied in a review of 768 coronal CT images. Type I cells were the most common cells to be found (14.9\%), followed by type VI cells in 3.1\%, and type II cells in $1.7 \%$ of the study population. ${ }^{7}$ The greater incidence of frontal sinusitis in this series was not related to the presence of frontal cells in this study. There was also no association between the size of the frontal isthmus and the presence of frontal sinusitis. Similarly, the agger nasi cell was present in $86.7 \%$ of cases, and interfrontal cells were seen in $12.2 \%$ of the cases studied. There was no relation between the presence of agger nasi cells and the incidence of frontal sinusitis. ${ }^{4}$

Persistent obstruction of the frontal infundibulum is found to be a major cause of failure of endoscopic sinus surgery. ${ }^{13}$

When the frontal sinus shows mucosal thickening of more than $>3 \mathrm{~mm}$ involving the entire sinus cavity or the most dependent part, it is considered to be frontal sinuisitis. ${ }^{14}$

\section{Discussion}

\section{Types of Frontal Cells}

DelGaudio et al. reported the prevalence to be $33 \%$ in a CT study of 106 patients. Type I cells were found in $18.4 \%$ of the study population, type II was found in $2 \%$, type III was found in $6.1 \%$, and type IV was found in $3.1 \%$ of the population studied. ${ }^{1}$ Meyer et al. observed that the frontal cells had a prevalence of $20.4 \%$ in a study of 768 coronal CT scans, where type I cells were found in $14.9 \%$ of cases studied, type II were found in 3.1\%, type III were found in $1.7 \%$, and type IV were found in $2.1 \%$ of the cases studied. ${ }^{7}$

According to Lee et al., type I cells were found in as many as $37 \%$ of the cases studied, type II cells were found in 19\%, type III cells were found in $8 \%$, and type IV cells were found in $0 \%$ of the cases studied. ${ }^{12}$

Kew et al. found that there was no statistical significance between the presence of frontal cells and the development of frontal sinusitis after assessing CT images of frontal recess in 43 patients. $^{8}$

\section{Diameter and Area of the Frontal Ostium}

DelGaudio et al. found that there was no relation between the size of the frontal recess and the occurrence of chronic frontal sinusitis. ${ }^{1}$

Landsberg et al. reported the dimensions of the frontal ostium being as follows: $7.22 \mathrm{~mm}$ anteroposteriorly (with a SD of $2.78 \mathrm{~mm}$ ) and $8.92 \mathrm{~mm}$ transversely (with a SD of $2.95 \mathrm{~mm}$ ). The mean sectional frontal ostium area was found to be $50.5 \mathrm{~mm}^{2} .4$

\section{Frontal Cells and Frontal Sinusitis}

Most studies on CT analysis of frontal sinus outflow tract have been done in patients with chronic sinusitis or no sinusitis, with only a few studies assessing the prevalence of frontal cells, and fewer 
still investigating the association of frontal cells and occurrence of frontal sinus disease.

A study on the occurrence of frontal sinusitis in patients with frontal cells by DelGaudio et al. in 106 patients using multiplanar CT scans, identified frontal cells in 33\% of patients, and found that frontal cells and agger nasi cells did not contribute to a higher incidence of chronic frontal sinusitis. ${ }^{1}$

Meyer et al. studied the coronal CT scans of paranasal sinuses in a large population and found the prevalence of frontal cells to be $20.4 \%$. They also found an increased incidence of frontal sinus disease in those cases with type III and IV frontal cells.?

\section{ConcLusion}

Frontal cells were found to occur in some frontal recesses, the most common type of cells being type I cells. We found that the incidence of frontal sinusitis and the size of the frontal isthmus had no correlation. We also concluded that mucosal inflammatory processes are likely to be a more important etiologic factor, although anatomic variations in the frontal infundibulum also play a role in chronic frontal sinusitis.

\section{References}

1. DelGaudio JM, Hudgins PA, Venkatraman G, Beningfield A. Multiplanar computed tomographic analysis of frontal recess cells: effect on frontal isthmus size and frontal sinusitis. Arch Otolaryngol Head Neck Surg 2005;131(3):230-235. DOI: 10.1001/archotol. 131.3.230.

2. Van Alyea OE. Frontal cells: an anatomic study of these cells with consideration of their clinical significance. Arch Otolaryngol 1941;34(1):11-23. DOI: 10.1001/archotol.1941.00660040021003.

3. Stammberger $\mathrm{H}$, Posawetz W. Functional endoscopic sinus surgery. Eur Arch Otorhinolaryngol 1990;247(2):63-76. DOI: 10.1007/ BF00183169.
4. Landsberg R, Friedman M. A computer-assisted anatomical study of the nasofrontal region. Laryngoscope 2001;111(12):2125-2130. DOI: 10.1097/00005537-200112000-00008.

5. Jacobs JB. 100 Years of frontal sinus surgery. Laryngoscope 1997;107(S83):1-36. DOI: 10.1097/00005537-199711001-00001.

6. McLaughlin RB, Rehl RM, Lanza DC. Clinically relevant frontal sinus anatomy and physiology. Otolaryngol Clin North Am 2001;34(1):1-22. DOI: 10.1016/S0030-6665(05)70291-7.

7. Meyer TK, Kocak M, Smith MM, Smith TL. Coronal computed tomography analysis of frontal cells. Amer J Rhinol 2003;17(3): 163-168. DOI: $10.1177 / 194589240301700310$.

8. Kew J, Rees GL, Close D, Sdralis T, Sebben RA, Wormald PJ. Multiplanar reconstructed computed tomography images improves depiction and understanding of the anatomy of the frontal sinus and recess. Amer J Rhinol 2002;16(2):119-123. DOI: 10.1177/194589240201600209.

9. Sagar GR, Jha BC, Meghanadh KR. A study of anatomy of frontal recess in patients suffering from 'chronic frontal sinus disease'. Indian J Otolaryngol Head Neck Surg 2013;65(2):435-439. DOI: 10.1007/ s12070-013-0653-7.

10. Basak S, Karaman C-Z, Akdilli A. Evaluation of some important anatomicalvariations and dangerous areas of the paranasal sinuses by CT for safer endonasal surgery. Rhinology 1998;36(4):162-167.

11. Lee WT, Kuhn FA, Citardi MJ. 3D computed tomographic analysis of frontal recess anatomy in patients without frontal sinusitis. Otolaryngolo Head Neck Surg 2004;131(3):164-173. DOI: 10.1016/j. otohns.2004.04.012.

12. Jacobs JB, Shpizner BA, Brunner E, Lebowitz RA, Holliday RA. Role of the aggernasi cell in chronic frontal sinusitis. Ann Otol Rhinol Laryngol 1996;105(9):694-700. DOI: 10.1177/000348949610500905.

13. Turgut S, Ercan I, Sayın I, Başak M. The relationship between frontal sinusitis and localization of the frontal sinus outflow tract: a computer-assisted anatomical and clinical study. Arch Otolaryngol Head Neck Surg 2005;131(6):518-522. DOI: 10.1001/archotol. 131.6.518.

14. Coates MH, Whyte AM, Earwaker JWS. Frontal recess air cells:spectrum of CT appearances. Australas Radiol 2003;47(1):4-10. DOI: 10.1046/ j.1440-1673.2003.t01-1-01124.x. 